\title{
Providing Services for Students with Disabilities in an Academic Library
}

\author{
By Catherine J. Carter, DeVry University, Chicago
}

\begin{abstract}
Accessibility issues are at the forefront of library services as the number of students with disabilities
attending colleges or universities continues to increase. Three areas where academic librarians can
concentrate efforts to better meet the needs of these students are: bibliographic instruction, web page
design, and staff training. While the suggestions presented here focus on providing enhanced service to
students with disabilities, all students can benefit from increased sensitivity and understanding of different
learning styles, improved quality of library service to better enable students to conduct research
independently, and easier access to information.
\end{abstract}
Librarians and their affiliated institutions have long been philosophically proactive in providing equal access to information for everyone. In addition to a natural proclivity for this attitude, there are number of laws that require this posture. The American with Disabilities Act (ADA) guarantees that people with disabilities are given "equal opportunity for employment (Title 1), equal access to public services (Title II), and public accommodations and services provided by private entities (Title III). Title II particularly impacts libraries and librarians. Equal access to public services requires that libraries not only become physically accessible to all disabled users, but that all services are adequately adapted to meet the special needs of these individuals" (Applin, 1999, 139).

Prior to the adoption of the ADA, most college and university libraries had "at least some rudimentary access programs and initiatives in place...because most colleges and universities are recipients of federal funding and, as such, have been subject to the provisions outlined in Section 504 of the Rehabilitation Act since 1973" (McNulty, 1999, p. 9). However, accessibility issues continue to be at the forefront of library service as the number of Americans with disabilities, including those attending colleges or universities, increases. In 1978, $2.6 \%$ of full-time college or university freshmen were labeled as having a disability compared to $7.8 \%$ in 1985 and one of eleven first year students in 1996 (Wilhelmus, 1996). McNulty (1999) notes "disability in the 1970s meant, for the most part, physical disability" (p. 7). Since that time, many colleges and universities have experienced an increase in the number of students with learning disabilities. A 1979 study reported that only $3.1 \%$ of college freshmen identified themselves as having a learning disability. It is estimated that the percentage of freshman college student with learning disabilities has tripled since that time; however, an accurate number is difficult to determine as some students do not identify themselves as having learning disabilities (McNulty, 1999).

Providing equal access to library services is a continuous process that must be evaluated periodically as new technologies become available and impact how we access and utilize information resources. This paper will focus on three areas where academic librarians can focus their efforts to continue to meet the needs of students with disabilities: a) bibliographic instruction; b) web pages; and, c) staff training.

\section{Bibliographic Instruction}

One of the key services that academic librarians provide to students is bibliographic instruction, or library instruction, in how to access and evaluate information resources available through the library. The goals of library instruction are "the same for library users with disabilities as they are for other library users: to assist the patron to use the library resources effectively and to support present and future learning" (Miller-Gatenby \& Chittenden, 2000, 320). Oftentimes, however, in- 
structional sessions are not designed with the needs of special population students in mind. "It is only when an individual with a disability requests such services that librarians mobilize to try to gather the necessary background information, tools, and/or appropriate equipment to provide adequate learning experiences" (Applin, 1999, 139).

There are many reasons why this situation may occur. In large colleges and university libraries, a library liaison works with the institution's office for students with disabilities. DeCandido (1999) observes,

The university office is the source for most of the information about whom the liaisons serve, for the kinds of equipment the library needs to purchase, and, in some cases, is the source of funding for assistive technology. Students with disabilities register with the university office and attend orientations and other programs sponsored by that office, at which librarians usually give presentation and provide written materials in various forms. (p. 8)

This is not always the case in small academic libraries where little advance notice is received that there are students with disabilities enrolled that may need specialized services, or in many cases where the disability is not readily identified as with learning disabilities. Even so, librarians must take a proactive approach rather than a reactive one in reaching those students with disabilities as well as those students without disabilities.

Specialized instruction sessions can be developed for those who request them. These can be especially effective with students who have physical disabilities and need to use assistive technologies such as "software that reads text aloud, responds to verbal commands, makes web pages audible, puts voice output on disk, enlarges computer screen images, etc." (DeCandido, 1999, 7). Many students, however, do not wish to disclose their disabilities even tough it may mean they must struggle harder with their studies. Librarians must recognize this fact and use teaching methods to assist students with disabilities that can also benefit those students without disabilities. By incorporating these teaching methods into their presentations, library instructors avoid calling unnecessary attention to the patron with the disability which may make her or him feel self-conscious and uncomfortable (Applin, 1999).

Applin (1999) suggests developing a multisensory teaching style that "includes appropriate visual, aural, and tactile techniques to meet the needs of every kind of learner" (p. 140). The basic strategy for this type of instruction is to "include short, specific, verbal instructions or explanations; simple, large, visual representations; and immediate, hands-on experience. No matter what the learning style of the patron, a primary strategy is provided with secondary reinforcement given through the use of the other two techniques" ( $p$. 140).

Some additional considerations in adapting bibliographic instruction to meet the needs of all students are listed below:

- Provide oral and written instructions and repeat key points. Rephrase your sentences or questions if a person does not understand you. This is especially important for students who are deaf or persons with a learning disability or attention deficit disorder (MillerGatenby \& Chittenden, 2000, 322).

- Use easily understandable language. Explain unfamiliar or technical words but use "plain, understandable language in explanations and handouts. Patrons with perceptual and neurological disorders...have a hard time following innuendos, inferences and underlying messages we use in the English language. Their use should be avoided" (Applin, 1999, 141).

- Follow a concise, sequential lesson plan. "Patrons with neurological disorders (e.g., attention deficit disorders or traumatic brain injuries) have a hard time following lectures or directions which are not concise and sequential" (Applin, 1999, p. 141). Focus on the most essential items necessary for a student to know and avoid "long, unnecessary explanations or irrelevant stories. An outline at the beginning or class and a summary at the conclusion of the class is helpful" (p. 141).

\section{Web Pages}

Libraries are continuously increasing their use of electronic resources such as online catalogs, fulltext newspaper, journal and periodical articles, CD-ROMs, and multi-media reference publications such as encyclopedias and dictionaries. Additionally, libraries are also designing their own web pages that provide links to these electronic resources, promote and encourage the use of the library's services and collections, and provide tutorials on utilizing these resources.

Accessing these resources can be difficult for users with disabilities. According to the Texas State Library and Archives Commission (2004), three general categories of limitations that create diffi- 
culties for those accessing web pages can be identified:

- Sensory Limitations. Screen readers, large type or high contrast text and background combinations can accommodate blindness or low vision. Web designers can use descriptive tags to explain images and tables.

- Physical Limitations. People who are unable to use a standard keyboard can use onscreen keyboards or other assistive technologies. People who are unable to use a standard mouse can use keyboard shortcuts or other assistive technologies.

- Cognitive Limitations. People who have difficulty processing visually can use screen magnification tools. Pages with simple color schemes and limited animation also help people with cognitive disabilities.

Library webmasters are continuously trying to make library web sites more user-friendly to individuals with disabilities. However, there is a constant demand for multimedia presentations, interactive applications, and information-rich web sites that conflict with this goal. A set of United States federal standards known as Section 508 provides clear guidelines for creating more user-friendly web sites. Hudson (2002) notes:

Section 508 falls under the Rehabilitation Act of 1973 which requires that federal agencies make adjustments for those with visual, audio, mobility, and cognitive impairments...the 1998 law specifically applies to electronic information technology. Its main purpose is to create government-wide accessibility standards for anyone who uses the web or owns software, desktop computers, video and telecommunications products, and other information technology. ( $p$. 19)

Section 508 standards are not the first set of guidelines developed for web site accessibility. The most well known of these are those put forward by the World Wide Web Consortium's Web Accessibility Initiative (WAI). The Section 508 guidelines add to the WAl guidelines by providing a "clear, concise, and codified set of standards and a commitment by the federal government to not only comply with these standards but require that vendors do so as well" (Hudson, 2002, 21).

While Section 508 standards apply to federal agencies, they may also apply to university libraries that receive state funding. Conflicting interpretations of the law exists with the legal counsel for the California Community Colleges Chancellor's Office (CCCCO) and the California State Univer- sity Chancellor's Office stating that "without Congressional legislation, the Department of Education lacks authority to compel states to comply with section 508," (Hudson, 2002, 22) while on the other hand, the CCCCO states, "these regulations are applicable to the states by virtue of the Assistive Technology Act of 1998 memo" (Hudson, $2002,22)$. Hudson observes that no one will know definitively if Section 508 applies to states until it has been determined through case law. This may not happen for years, as many of these cases are settled out of court; however, "since universities and public libraries can be sued under the Americans with Disabilities Act, conformity with Section 508 standards for web sites demonstrates our effort to serve all of our patrons equally" (Hudson, 2002, 22).

Section 508 criteria for web-based technology and information are based on access guidelines developed by the Web Accessibility Initiative of the World Wide Web Consortium" (U. S. General Services Administrators' Office of Government-wide Policy, 2002, 2). These guidelines, containing 14 primary areas, and 64 specific checkpoints within those areas, are exhaustive and can be viewed in their entirety at the W3C website. Sample World Wide Web Consortium (2004) recommended guidelines follow:

- Provide a text equivalent for ever non-text element, i.e., images, graphical representations of text (including symbols), sound, and audio files

- Ensure that all information conveyed with color is also available without color

- Use captions and headings to group text logically

- Organize documents so they may be read without style sheets

- Use the clearest and simplest language appropriate for a site's content

- Identify row and column headers of tables

- Provide a textual description of a multimedia presentation

- Allow users to control flickering, avoid causing screens to flicker.

Existing web pages can be checked with an accessibility evaluator such as "Bobby". Bobby was created by the Center for Applied Special Technology and is available free of charge. Bobby is simple to use: merely type in the URL of the web page you want to check on the Bobby form. Bobby evaluates the page using $W 3 C$ guidelines, lists problems that affect a user's accessibility, and ranks them in order of priority. Many prob- 
lems can be easily modified or adjusted to make the web site more accessible to users with disabilities.

Blake (2000) used Bobby to evaluate web sites of 13 public university libraries, 7 private college and university libraries, and 12 community and technical college libraries located in Arkansas. She found that $43 \%$ of private universities and colleges were compliant with W3C guidelines, public universities had a compliance rate of $38 \%$, and community and technical colleges had a compliance rate of $25 \%$. Clearly, if results of the Arkansas libraries tested are any indication, the majority of college and university library web pages need improvement to comply with $\mathrm{W} 3 \mathrm{C}$ guidelines.

\section{Staff Training}

A critical component to providing equitable access service is the interaction between students with disabilities and library staff. A survey of students with disabilities at Northern Illinois University was conducted to "find out what elements of the library's Services for Student with Disabilities were most useful to them; what the students really wanted and needed; and, how the program should be changed or developed" (Curry, 1991, 479). Eighty-five percent of the respondents "felt that the people who help them at the library were more useful to them than any other part of the program" (Curry, 1991, 480). One student at the University of Missouri-Kansas City noted, "the attitudes of those [library staff] interacting with them [students with disabilities] were often more important than their actual words" (Graubart, 1996, 39). DeCandido (1999) reported that one student at another university, who is blind, said, "staff attitudes 'totally make all the difference' in ease of library use...she would often spend more than 12 hours a day in the library, scanning material she needed. She stressed that one bad experience in the library can turn a person with disabilities away permanently" (p. 27).

Library staff may feel uncomfortable and selfconscious when assisting those with disabilities. They may have "preconceptions and misconceptions about persons with certain disabilities and may be unaware that some disabilities are invisible and not readily apparent to others" (MillerGatenby \& Chittendon, 2000, 319). It is only through adequate training that staff can be "sensitized to the special needs of people with disabilities and help them feel more comfortable interacting with them" (Applin, 1999, 140).
The first step when implementing such a training program is to assess the need for and the scope of the sessions. According to Deines-Jones (1999), "training needs often are determined without consulting staff members or patrons to find out not only what staff members do not [italics added] know, but also what they should [italics added] know. When training needs are defined and staff members know why the training is important, they will be more willing participants and more likely to retain and use information" (p. 148). Questionnaires are useful in obtaining information necessary to prioritize the types of training needed. For example, if most staff members are comfortable assisting patrons in using adaptive technology, this type of training could become a lower priority than the training needed to improve awareness and sensitivity in assisting those with learning disabilities.

Deines-Jones (1999) classified training into four general categories:

- Attitudinal training designed to improve awareness of and sensitivity to disabilityrelated issues;

- Facility training: people are trained to use equipment or make physical facilities accessible;

- Service training aimed at teaching staff to design programs and services which are accessible to all;

- Legal training that explains the letter and requirements of the law, whether the ADA or other legislation. (p. 153).

\section{Attitudinal Training}

Attitudinal, or sensitivity, training is the most difficult type of barrier to equitable service to overcome. The most effective way to improve attitudes toward people with disabilities is through "expanded on-the-job exposure to people with disabilities. Unfortunately, attitudinal barriers prevent many potential library users from visiting the library frequently," (Deines-Jones, 1999, 153) thus formalized training sessions become necessary.

Information sharing is an effective way to address attitudinal barriers. In this activity, persons with disabilities are invited to speak about their experiences, both positive and negative, in the library and relate how staff members' attitudes affect them. Graubart (1996) found the following:

Participants reported that listening to and speaking with the panelists definitely increased their sensitivity and promoted insights for interacting with people with disabilities...several people commented on a blind student remark- 
ing that people sometimes raised their voices or did not identify themselves when speaking to him...he also noticed when people seemed to be scurrying away to avoid him when he approached. Several respondents also stated that they heard a similar reaction from a student who used a wheelchair who said that he noticed when people seemed to try to avoid him (p. 39).

Role playing is a device frequently used in sensitivity training sessions. Having participants wear dark glasses to simulate being blind and "reading" information on a web site through a speech simulation device or being in a wheelchair to experience difficulties encountered when simply trying to obtain a book on an upper shelf is an effective way to promote insights into difficulties patrons with disabilities encounter when using the library.

Deines-Jones (1999) notes "role playing can reveal interesting prejudices about people with disabilities. In awareness sessions demonstrating how credible librarians find people with disabilities, students and practicing librarians alike tend to extend more sympathy to and are more likely to believe people who have obvious disabilities" ( $p$. $154)$ than those who do not. She uses two example of role playing to demonstrate this.

In the first role-play, a female library page is aware of a male student in a wheelchair who keeps staring at her. His hands keep making a jerking motion and something about him is very unsettling to her. She is busy shelving books, not paying attention to her surroundings, when she is suddenly startled by the student in the wheelchair appearing next to her. As she turns towards him, his hand suddenly jerks and clutches at her breast. The page goes to her supervisor to report the incident. The student explains that he was simply reaching for a book and was unable to control his movements because of his disability and how dare the page make an accusation that he did something wrong. This role-play centers on how this incident should be resolved. (In reality, the student is a pervert who discovered that if he fakes muscular spasms, he can get away with groping young women.)

In the second role-play, a student with a learning disability needs to use a computer in the computer lab. It is Sunday night and the lab is jammed; all computers are in use and there is a waiting line. The only available computer is reserved for persons with disabilities. The student has a learning disability and received an ID with a special access sticker on it, allowing her to use the reserved com- computer. Unfortunately, she lost her ID and her wallet. She cannot get a new ID until tomorrow but her paper is due then as well. She approaches the information desk to explain her situation and get permission to use the computer. The role play centers on how this incident is resolved-should the student be allowed to use the special access computer without proper authorization?

Deines-Jones (1999) found that "with very few exceptions, people do not even consider the possibility that the man who uses a wheelchair might be a pervert, but they tend to be extremely distrustful of the young woman who claims to have a learning disability" (p. 154). These exercises demonstrate that "people with disabilities are not all saintly people to be alternately pitied and admired but, rather, are library patrons like all others, with potentially different information access strategies" (Deines-Jones, 1999, 154).

\section{Facility Training}

Facility training focuses on the accessibility of libraries and the operation of adaptive equipment. Role-playing and simulation exercises can be effective training tools. Simulating a library patron in a wheelchair navigating the physical area of the library including using the elevator, accessing washrooms, moving through the stacks, attempting to reach books on upper and lower shelves are effective ways of making staff members aware of the difficulties patrons with physical disabilities encounter. Exercises can be developed to simulate patrons with vision and hearing impairments and learning disabilities. Staff need to know how to operate various equipment that are available. "Facility training also gives staff members the tools they need to evaluate what facilities or equipment may not be fully accessible so that they can either design measures to increase accessibility or devise work-around strategies" (Deines-Jones, 1999, 157).

\section{Service and Legal Training}

Service training is closely aligned with attitudinal training and facility training. Service training is used to focus on how to overcome attitudinal and facility barriers to universal access for all library patrons. The goal of the library is not how to make the library accessible to those with disabilities but how to ensure that "all library services are accessible to its entire user base" (Deines-Jones, 1999, p. 158). Service training enables staff members to identify creative solutions to accommodate those with special needs without "compromising ser- 
vices to students who do not have disabilities" (Deines-Jones, 1999, 158).

Additionally, professionals with proper credentials should provide legal training. It is important for all staff members to understand the basics of the $\mathrm{ADA}$ and the history of disability rights. Staff members act as representatives of the library and must be aware that their actions, or inactions, can result in legal ramifications against the library.

\section{Conclusion}

Academic librarians have implemented policies and procedures to ensure equitable access to information resources for student with disabilities as a result of legislation such as the Rehabilitation Act of 1973, the Americans with Disabilities Act of 1990, and Section 508 federal standards, and a philosophical belief in access for all. The purpose of the legislation enacted that affects library service for people with disabilities is to ensure that they have equal rights to information services and not special rights that continue to keep them disenfranchised and excluded from the rest of the student body. Students with disabilities do not want to be singled out as being different or needing special services. This is made clear through the increasing number of students with "invisible" disabilities such as learning disabilities in our colleges and universities today who do not wish to register with an institution's office for students with disabilities.

Equitable access is a concept that benefits not only those students with disabilities but those without disabilities as well. Adapting a multisensory teaching style that uses a variety of visual, aural, and tactile techniques meets the needs of every kind of learner. Creating web sites that make information more accessible not only benefits individuals with disabilities, but aids users in a variety of contexts whether they are using a desktop browser, a mobile phone, or working in a hands-free environment. Focusing on clarity of information and easier access allows all users to access information on the web more quickly. Finally, staff training issues benefit all users through increased sensitivity and understanding of users' needs, improved quality of library service to better enable students to conduct research independently, and improved access to information. As methodologies and technologies change, it is necessary that these issues are constantly reviewed and new processes implemented to continue to meet the concepts of equitable access.

\section{References}

Applin, M. (1999). Instructional Services for Students with Disabilities. Journal of Academic Librarianship, 25, 139-142.

Blake, S. E. (2000). Universal Access, the ADA, and Your Library Web Page. Arkansas Libraries, 57, 19-24.

Curry, E. (1991). Ask So You Can Give: Reference/research Service for the Disabled in an Academic Library. RQ, Summer, 479-485.

DeCandido, G. (1999). Service to Users with Disabilities. Washington, DC: Association of Research Libraries.

Deines-Jones, C. (1999). Training Professional and Support Staff Members. In T. McNulty (Ed.), Accessible Libraries on Campus. Chicago: ACRL.

Graubart, M. (1996). Serving the Library Needs of Students with Physical Disabilities. Library Hi Tech, 14, 37-40.

Hudson, L. (2002). A New Age of Accessibility. Library Journal, 127, 19-22.

McNulty, T. (Ed.). (1999). Accessible Libraries on Campus: A Practical Guide for the Creation of Disability-friendly Libraries. Chicago: ACRL.

Miller-Gatenby, K. J., \& Chittenden, M. (2000). Reference Services for All: How to Support Reference Service to Clients with Disabilities. The Reference Librarian, 69/70, 313-336.

Texas State Library and Archives Commission. (2005). Creating ADA-compliant Web Sites. Retrieved Feb. 21, 2005, from http://www.tsl. state.tx.us/ld/pubs/ada.

United States. General Services Administration's Office of Governmentwide Policy (n.d.). Section 508. Retrieved February 21, 2005, from http://www. section508.gov.

Wilhelmus, D. W. (1996). Perspectives on the Americans with Disabilities Act. Journal of Academic Librarianship, 22, 366-371.

Watchfire Corporation. (2005). Welcome to Bobby. Retrieved February 21, 2005, from http://bobby.watchfire. com/ bobby/html/en/ index.jsp.

World Wide Web Consortium (W3C). (2005). Checklist of Checkpoints for Web Content Accessibility Guidelines 1.0. Retrieved February 21, 2005, from http://www.w3.org/TR/WAlWEBCONTENT/full-checklist.html

Catherine J. Carter, DeVry University, Chicago. Email: cjcarter@chi.devry.edu 